\title{
World Journal of Emergency

\section{Emergency room surgical workload in an inner city UK teaching hospital}

\author{
Tuong A Mai-Phan ${ }^{1}$, Bijendra Patel ${ }^{1,2}$, Michael Walsh ${ }^{2}$, Ajit T Abraham ${ }^{2}$ and \\ Hemant M Kocher*1,2
}

Address: ${ }^{1}$ Institute of Cancer, Barts and the London School of Medicine and Dentistry, London, UK and ${ }^{2}$ The Department of General Surgery, The Royal London Hospital, Barts and the London NHS Trust, Whitechapel, London E1 1BB, UK

Email: Tuong A Mai-Phan - benhviengiadinh@yahoo.ca; Bijendra Patel - b.patel@qmul.ac.uk;

Michael Walsh - michael.walsh@bartsandthelondon.nhs.uk; Ajit T Abraham - ajit.abraham@bartsandthelondon.nhs.uk;

Hemant M Kocher* - hemant.kocher@bartsandthelondon.nhs.uk

* Corresponding author

Published: 30 May 2008

World Journal of Emergency Surgery 2008, 3:19 doi:10.1186/1749-7922-3-19

This article is available from: http://www.wjes.org/content/3/1/19

(c) 2008 Mai-Phan et al; licensee BioMed Central Ltd.

This is an Open Access article distributed under the terms of the Creative Commons Attribution License (http://creativecommons.org/licenses/by/2.0), which permits unrestricted use, distribution, and reproduction in any medium, provided the original work is properly cited.
Received: 13 February 2008

Accepted: 30 May 2008

\begin{abstract}
Background: Emergency admissions may account for over $50 \%$ of surgical admissions. The impact on service provision and implications for training are difficult to quantify. We performed a cohort study to analyse these workload patterns.

Methods: Data on emergency room (ER) surgical admissions over six months was collected including patient demographics, referral sources, diagnosis, operation and length of stay and analysed according to sub-speciality and age-groups.

Results: There were I392 (median age 4I (IQR 28-60) years, M:F = I.7:I) emergency surgical admissions over six months; $45 \%$ were under 40 years of age and $48 \%$ patients self-referred to the ER. The commonest diagnoses were abscesses (1I\%), non-specific abdominal pain $(9.7 \%)$ and neuro-trauma $(9.6 \%)$. The median length of stay was 4 (IQR 2-8) days; with older ( $>80$ years) patient staying significantly longer than those $<40$ years of age (median 8 vs 2 two days, $P<0.000$ I, Kruskal-Wallis test). Vascular patients remained in hospital longer than trauma or general surgery patients (median I 4 vs 3 days, $\mathrm{P}<0.000 \mathrm{I}$, Kruskal-Wallis test). A high proportion (43.5\%) of the patients required operative intervention and service implications of various diagnoses and operative interventions are highlighted.
\end{abstract}

Conclusion: With the introduction of shortened training period in Europe and World over, trainees may benefit from increased exposure to trauma and surgical emergencies. Resource planning should be based on more comprehensive, prospective data such as these.

\section{Introduction}

Emergency surgical admissions account for $46 \%$ to $57 \%$ of all surgical admissions [1-3] but workload estimates are difficult to achieve because of the unpredictability and variability of such admissions. There are no contempora- neous studies concerning the nature and volume of emergency surgical admissions. The impact of the emergency surgical workload on surgical practice is not only determined by overall volume but also by patient demographics, appropriateness of referral, centralisation, diagnoses, 
and required surgical operations. [4] The changing patterns have implications for surgical training, workforce planning and service provision. [2] The Royal London Hospital, a multi-specialty inner city teaching hospital which provides London's only Air Ambulance caters to a young, ethnically \& socio-economically diverse, mainly immigrant population. [5] Health services in London are to be reconfigured, with fewer centres catering to larger populations and this similar exercise is being carried out in different parts of the world for macro- and micro-economic reasons without adequate data on volume, length of stay and problems for various specialties in hospitals. [6] This study sought to identify the current patterns and common problems related to emergency room (ER) admissions from a single hospital.

\section{Methods}

All ER surgical admissions over six months (12 January 11 July 2007) to accident and emergency department were recorded prospectively. Orthopaedic trauma only (not polytrauma) and urological admissions were excluded since they were managed by orthopaedic and urology departments respectively; patients referred internally (already in-patient for another medical condition) from other specialties were also excluded since they did not effect the surgical department's bed occupancy rates. Information was obtained from hand-over lists and the Electronic Patient Record (EPR) viewer, an intranet-based patient record of Barts and The London NHS Trust. All data were anonymised and recorded in password protected spreadsheets. Information regarding time of operation was extracted from theatre logs. The final diagnosis was determined after investigations and/or operation and all patients were followed-up till discharge. One overnight stay was classified as 1 day of stay for length of stay calculations. Statistical analysis (ANOVA and Kruskal-Wallis test for data with and without normal distribution respectively) were performed on SPSS 14.0 for Windows (SPSS UK Ltd, Surrey, UK).

\section{Results}

1775 emergency surgery referrals were recorded, of which 1392 (870 (62\%) male, median age 41 (Inter-quartile range (IQR) 28-60 years) were admitted for further treatment over a six month period resulting in a mean of 7.2 admissions per day, with Saturdays being the days with least admissions (ANOVA, $\mathrm{df}=6, \mathrm{~F}=2.149, \mathrm{P}=0.05$; Figure 1). Forty five per cent (402) admissions were under 40 years of age. The busiest time of day for admission was between 12.00 and 18.00 hours when $(36 \%)$ were admitted (ANOVA, $\mathrm{df}=3, \mathrm{~F}=24.42, \mathrm{P}<0.001$, Figure 2). Interestingly GP (General Practitioner) referrals (those patients vetted initially by family physicians) formed only $11 \%$ of all emergency surgical admissions (Figure 3). Trauma patients were significantly younger than vascular patients

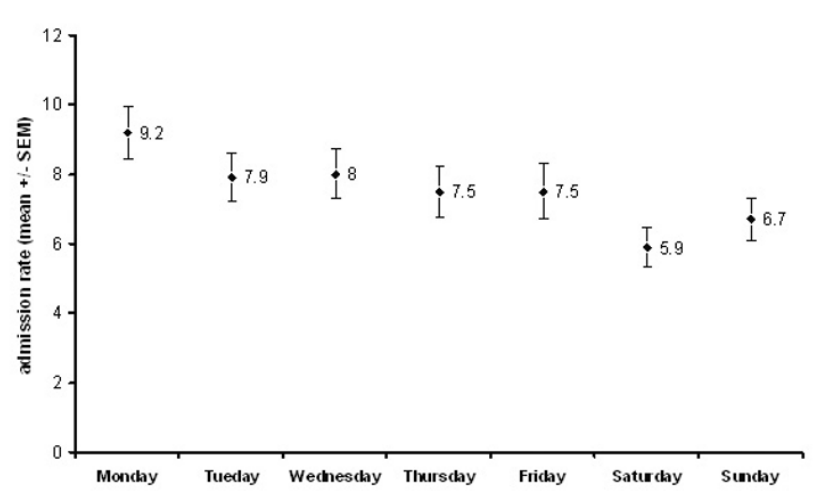

Figure I

Admissions per day of the week. Results are expressed as mean \pm standard error of mean.

(Kruskal-Wallis, $\mathrm{df}=2$, Chi-square statistic $=196.2, \mathrm{P}<$ 0.001; Figure 4).

\section{Diagnoses \& Operations}

Table 1 details the distribution of patients according to specialty, diagnosis, number of admissions as well as sex ratios, and length of stay. Abscesses (11\%), non-specific abdominal pain $(9.7 \%)$ and acute appendicitis (6.6\%) were the commonest general surgical diagnoses. Among trauma patients neurological injury $(9.6 \%)$ was the commonest reason for admission. As expected intuitively, male to female ratio was different according to specialties: vascular (2.8:1), trauma (4.4:1), general surgery (1.1:1). The younger patients ( $<40$ years) had a significant male preponderance $(1.8: 1)$ and the sex ratio became 1 only in over 80 year age group. Of all emergency surgical admissions, 605 (43.5\%) required operative intervention. More

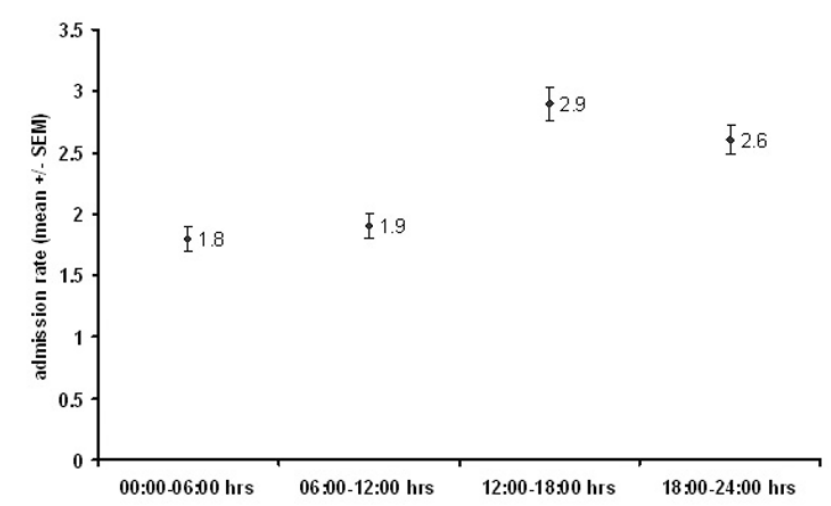

\section{Figure 2}

Timing of admission and peak hours. Results are expressed as mean \pm standard error of mean. 


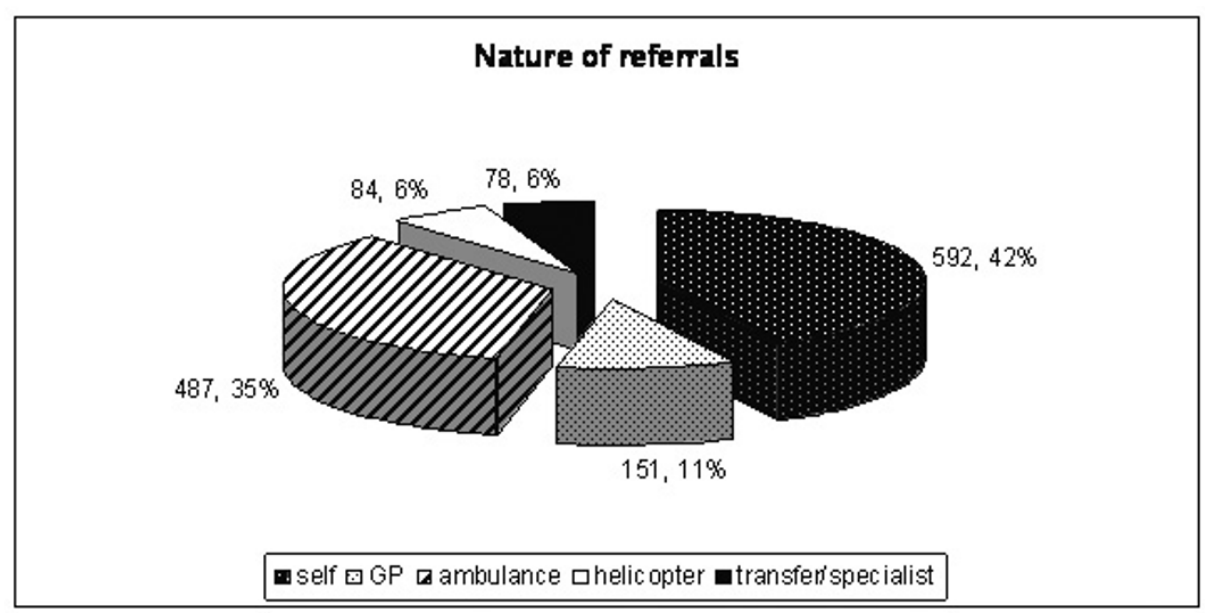

Figure 3

Nature of referrals.

than half (346 (57\%)) of general surgical emergency admissions required operative intervention while only $32 \%$ (195) of trauma and 11\% (64) of vascular emergencies required operative intervention. Types of operations, demographics, length of stay are detailed in table 2.

\section{Length of stay}

The median length of stay was $4(2-8)$ days. Vascular patients stayed in hospital significantly longer than trauma or general surgery patients (Kruskall Wallis, $\mathrm{df}=2$; Chi-square statistic $=106.8, \mathrm{P}<0.001$; Figure 5), possibly because most vascular patients were elderly. Elderly patients ( $>80$ years) stayed 6 days longer in the hospital as compared to those below the age of 40 years (Kruskall

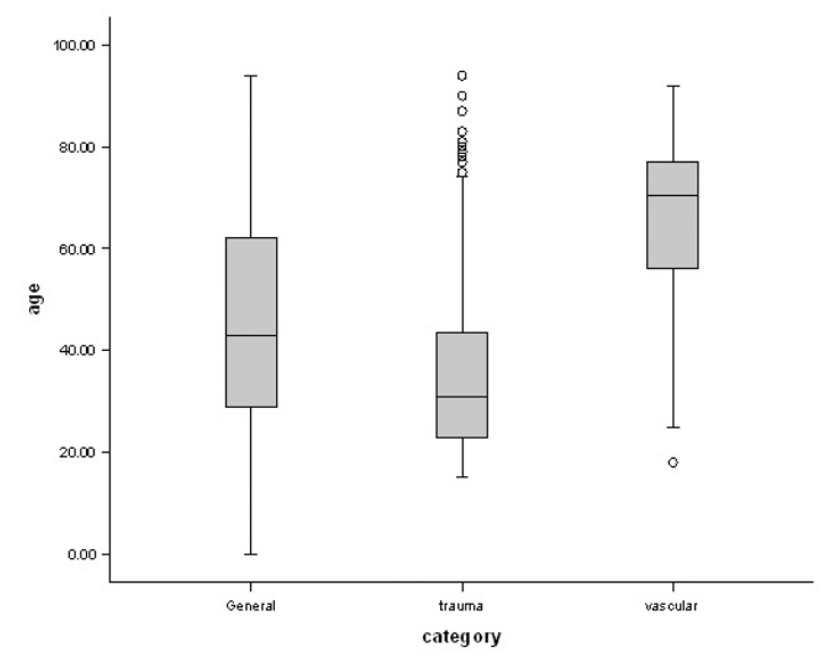

Figure 4

Median age per specialty distribution.
Wallis, $\mathrm{df}=3$; Chi-square statistic $=129.7, \mathrm{P}<0.001$; Figure 6). Patients who underwent surgery stayed a median of 4 days as compared to those without surgical intervention (3 days). It is worthwhile noting that laparoscopic appendicectomy patients stayed a median of 3 days as compared to 2 days for open appendicectomy. All abscesses stayed a median of 2 days in hospital.

\section{Discussion}

\section{Data uniqueness}

The strength of this contemporaneous data from one surgical department in the UK is prospective collection with complete follow-up, along with time of intervention. This allows us to get some estimates on the dynamic nature of emergency surgery, an aspect which is generally underestimated. Inevitably, a single centre data has limitations as to the generalizations which can be derived from them. In addition, there are other aspects of this work, which should be borne in mind. The Royal London Hospital serves a young, multiethnic, socio-economically deprived and diverse, largely immigrant population of the Tower Hamlets borough of London. This population has higher rates of accidental injuries than the rest of England. [5] It is, also, the site of the only Helicopter emergency medical service (HEMS) in London. [7,8] As a result, there is a higher intake of trauma patients, compared to the rest of the UK, who tend to be younger. This would explain lower median age of $41(28-60)$ years as compared to other UK studies [46.9 (range 12-99) years in 1984 and 52.6 years in 1998. [4,9-12] Though only $6 \%$ of patients were brought in by the HEMS, they considerably impacted on the workload $[8,9]$ as they were usually poly-trauma patients requiring muti-specialty care and investigational facilities as well as theatre space. Moreover, they also 
Table I: Common diagnoses

\begin{tabular}{|c|c|c|c|c|c|c|}
\hline Diagnosis & $\mathbf{N}(\%)$ & $M$ & $\mathbf{F}$ & Median age (IQR) & Mean LOS (SEM) & Median LOS (IQR) \\
\hline Trauma & 387 (27.9) & 315 & 72 & $31(23-44)$ & $9(0.8)$ & $3(1-9)$ \\
\hline Neuro trauma & $133(9.6)$ & 105 & 28 & $34(23-47)$ & $8(1.23)$ & $2(I-9)$ \\
\hline Thoracic trauma & $45(3.2)$ & 40 & 5 & $36(2 \mid-42)$ & $10(2.44)$ & $3(1-7)$ \\
\hline Abdominal trauma & $30(2.2)$ & 25 & 5 & $29(22-44)$ & $6(1.38)$ & $4(I-8)$ \\
\hline Orthopaedic trauma & $123(8.8)$ & 98 & 25 & $30(23-42)$ & $8(I)$ & $3(1-11)$ \\
\hline Vascular trauma & $3(0.2)$ & 2 & 1 & $32(30-70)$ & $4(1.45)$ & $4(2-7)$ \\
\hline Maxillo-facial trauma & $21(1.5)$ & 18 & 3 & $24(20-37)$ & $3(0.84)$ & $2(I-5)$ \\
\hline Poly trauma & 27 (1.9) & 24 & 3 & $30(22-44)$ & $27(6.18)$ & $10(4-52)$ \\
\hline Others trauma & $5(0.4)$ & 3 & 2 & $38(29-39)$ & $5(2.53)$ & $3(0-10)$ \\
\hline Vascular & $110(7.9)$ & 81 & 29 & $71(56-77)$ & $18(1.42)$ & $14(8-28)$ \\
\hline Abdominal aortic aneurysm & $25(1.8)$ & 21 & 4 & 77 (64-82) & $12(2.21)$ & $10(6-17)$ \\
\hline Ischaemic foot & $36(2.6)$ & 30 & 6 & $69(55-75)$ & $24(2.27)$ & $23(12-30)$ \\
\hline Embolic episodes & $12(0.9)$ & 6 & 6 & $6 I(49-73)$ & $16(4.47)$ & $9(7-19)$ \\
\hline Peripheral vascular diseases & $25(1.8)$ & 17 & 8 & $75(59-81)$ & $16(2.77)$ & $15(6-22)$ \\
\hline Others & $12(0.9)$ & 7 & 5 & $64(34-74)$ & $13(3.68)$ & $12(6-20)$ \\
\hline General surgery & $895(64.2)$ & 474 & 421 & $43(29-62)$ & $6(0.28)$ & $3(2-7)$ \\
\hline Appendicitis & $96(6.9)$ & 60 & 36 & $27(22-36)$ & $4(0.43)$ & $3(2-5)$ \\
\hline Abscess & $153(11.0)$ & 98 & 55 & $38(29-47)$ & $3(0.45)$ & $2(1-3)$ \\
\hline Hernia & $32(2.3)$ & 20 & 12 & $58(37-67)$ & $6(1.73)$ & $3(I-5)$ \\
\hline GDU perforation & $18(1.3)$ & 8 & 10 & $59(4 \mid-72)$ & $10(1.6)$ & $9(6-12)$ \\
\hline Pancreatitis & $55(4.0)$ & 30 & 25 & $50(37-60)$ & $9(0.9)$ & $4(2-7)$ \\
\hline Adhesion & $8(0.6)$ & 4 & 4 & $29(25-45)$ & $5(1.19)$ & $5(2-8)$ \\
\hline Obstruction & $26(1.9)$ & 16 & 10 & $67(40-74)$ & $\mathrm{II}(\mathrm{I} .8 \mathrm{I})$ & $7(5-15)$ \\
\hline Gallbladder disease & $67(4.8)$ & 24 & 43 & $42(29-70)$ & $8(1.1)$ & $4(2-9)$ \\
\hline Biliary tract disease & $15(1.1)$ & 7 & 8 & $56(4 I-63)$ & $5(0.87)$ & $4(2-6)$ \\
\hline NSAP & $135(9.7)$ & 63 & 72 & $37(27-55)$ & $5(0.7 I)$ & $3(1-5)$ \\
\hline Diverticular disease & $24(1.7)$ & 7 & 17 & $54(4 \mid-63)$ & $5(0.87)$ & $4(2-6)$ \\
\hline UGI bleeding & $5(0.4)$ & 3 & 2 & $54(46-59)$ & $15(7.11)$ & $11(4-13)$ \\
\hline LGI bleeding & $24(1.7)$ & 14 & 10 & $64(57-78)$ & $5(0.99)$ & $3(3-5)$ \\
\hline Malignacy & $31(2.2)$ & 13 & 18 & $61(50-69)$ & $12(2.52)$ & $9(3-16)$ \\
\hline Urology conditions & $27(1.9)$ & 21 & 6 & $51(31-67)$ & $4(1.57)$ & $2(I-5)$ \\
\hline Gyneacological conditions & $23(1.7)$ & 0 & 23 & $31(21-43)$ & $4(1.23)$ & $3(I-5)$ \\
\hline Medical conditions & $73(5.2)$ & 36 & 37 & $5 I(3 \mid-7 I)$ & $10(1.63)$ & $5(2-12)$ \\
\hline Others & $50(3.6)$ & 31 & 19 & $50(37-72)$ & $7(0.94)$ & $5(2-9)$ \\
\hline Post operative problems & $24(1.7)$ & 16 & 8 & $50(39-65)$ & $7(1.76)$ & $3(3-8)$ \\
\hline Miscellaneous & $9(0.6)$ & 3 & 6 & $54(38-59)$ & $6(1.49)$ & $6(2-9)$ \\
\hline Overall & 1392 & 870 & 522 & $41(28-60)$ & $8(0.32)$ & $4(2-8)$ \\
\hline
\end{tabular}

N: number. M: male. F: female. SEM: standard error of mean. IQR: interquatile range. GDU: gastroduodenal ulcer. NSAP: non-specific abdominal pain. UGI: upper intestinal. LGI: lower gastrointestinal.

tended to stay in hospital longer despite a younger median age (Table 1 ).

The incidence of common general surgical diagnoses such as abscess, and non-specific abdominal pain, was similar to those reported by Stower et al [12] and Irvin [11]. The much higher proportion of trauma admissions (28\%) compared to the 5.3\% reported by Stower et al [12] and to the $2 \%$ reported by Bain et al [9], is in keeping with the prominent role of a designated major trauma center for London. Only $11 \%$ of patients were referred by General Practitioner (GP) and there were a high proportion of selfreferral patients, and those brought in by ambulances (surface and air). Dookeran et al suggested that up to $41 \%$ of such admissions referred by General Practitioner were inappropriate [13] which could not be confirmed in our study.

\section{Timing of admissions and length of stay}

Monday was peak day of admission with Saturdays experiencing a dip which is different from results of Stower et al who demonstrated that there was no change of admission rate over the week. [12] Possible explanation could be proximity to a large work-force of over a million extra individuals over the working week in the City of London, a major financial services hub. Additionally, as can be expected the peak time for admissions during the day was from mid-day to mid-night, and this fact, makes a case for appropriate resource allocation. 
Table 2: Emergency operations.

\begin{tabular}{|c|c|c|c|c|c|c|}
\hline Operation & $\mathbf{N}(\%)$ & $M$ & $\mathbf{F}$ & Median age (IQR) & Mean LOS ( \pm SEM) & Median LOS (IQR) \\
\hline Trauma & $195(32)$ & 162 & 33 & $30(21-42)$ & $14.90(1.54)$ & $6(3-16)$ \\
\hline Laparotomy & $17(2.8)$ & 16 & 1 & $29(22-37)$ & $16.4(7.74)$ & $6(4-9)$ \\
\hline Thoracic procedures & $33(5.5)$ & 29 & 4 & $29(20-42)$ & $6.9(1.3)$ & $5(2-8)$ \\
\hline Neuro surgery & $30(5)$ & 23 & 7 & $35(21-42)$ & $24.2(4.16)$ & $16(12-29)$ \\
\hline Orthopaedic operations & $52(8.6)$ & 41 & 11 & $31(24-45)$ & $16.8(2.9)$ & $10(5-18)$ \\
\hline Maxillo facial operations & $6(1)$ & 4 & 2 & $18(17-22)$ & $8(2.84)$ & $5.5(4-7)$ \\
\hline Vascular operations & $6(1)$ & 5 & I & $31(25-32)$ & $14.3(9.98)$ & $5.5(2-7)$ \\
\hline Minor surgery & $36(6)$ & 34 & 2 & $29(20-42)$ & $2.8(0.5)$ & $2(I-3)$ \\
\hline Poly trauma & $15(2.5)$ & 13 & 2 & $32(24-44)$ & $39.7(7.97)$ & $38(8-65)$ \\
\hline Vascular & $64(11)$ & 48 & 16 & $72(62-77)$ & $24.8(2.65)$ & $18.5(10-31)$ \\
\hline AAA repair & $7(1.2)$ & 6 & I & $77(67-83)$ & $22(6)$ & $14(10-29)$ \\
\hline Bypass & $16(2.6)$ & 14 & 2 & 69 (59-77) & $25(4.8)$ & $21(13-32)$ \\
\hline Amputation & $23(3.8)$ & 17 & 6 & 71 (57-76) & $31(5.31)$ & $27(17-32)$ \\
\hline EVAR & $7(1.2)$ & 2 & 5 & 71 (49-87) & $19.4(7.07)$ & $9(7-3 \mid)$ \\
\hline Embolectomy & $10(1.7)$ & 9 & I & $77(64-82)$ & $14.5(4.83)$ & $8(8-16)$ \\
\hline Others & I $(0.2)$ & 0 & I & 72 & $17(0)$ & 17 \\
\hline General surgery & $346(57)$ & 248 & 98 & $36(26-50)$ & $6(0.5 I)$ & $3(2-6)$ \\
\hline Abscesses & 136 & & & & & \\
\hline Perianal Abscess & $55(9.1)$ & 42 & 13 & $4 \mid(32-48)$ & $2.4(0.24)$ & $2(I-3)$ \\
\hline IVDU-related Abscess & $32(5.3)$ & 16 & 15 & $34(28-44)$ & $3.1(0.77)$ & $2(I-3)$ \\
\hline Pilonidal Abscess & $12(2)$ & 7 & 5 & $28(21-37)$ & $2(0.33)$ & $2(I-2.5)$ \\
\hline Hydradenitis abscess & $2(0.3)$ & 2 & 0 & $41(39-42)$ & $2(0)$ & $2(2-2)$ \\
\hline Other abscess & $35(5.8)$ & 21 & 14 & $40(26-48)$ & $2.8(0.62)$ & $2(I-3)$ \\
\hline Laparoscopy & 74 & & & & & \\
\hline Laparoscopic appendectomy & $43(7.1)$ & 23 & 20 & $26(2|-3|)$ & $3.1(0.3)$ & $3(2-4)$ \\
\hline Laparoscopic DUP repair & $3(0.5)$ & I & 2 & $66(62-76)$ & $7(4.04)$ & $4(3-15)$ \\
\hline Laparoscopic Cholecystectomy & $17(2.8)$ & 7 & 10 & $44(34-59)$ & $9.2(2.84)$ & $6(4-9)$ \\
\hline Laparoscopic exploration & $7(1.2)$ & I & 6 & $23(|8-5|)$ & $6.9(1.95)$ & $6(3-10)$ \\
\hline Other laparoscopy & $4(0.7)$ & 2 & 2 & $52(39-65)$ & $17.3(5.85)$ & $15(8-26)$ \\
\hline Laparotomy & 135 & & & & & \\
\hline Laparoptomy appendicectomy & $5(0.8)$ & 2 & 3 & $39(37-57)$ & I (0.46) & $6(3-7)$ \\
\hline Open appendicectomy & $45(7.5)$ & 33 & 12 & $27(23-34)$ & $4.13(0.81)$ & $2(2-4)$ \\
\hline Open DUP repair & $6(1)$ & 5 & 2 & $41(35-72)$ & $9(3.06)$ & $6(4-8)$ \\
\hline Obstruction & $12(2)$ & 7 & 5 & $60(38-73)$ & $24.3(5.73)$ & $16(7-37)$ \\
\hline Other laparotomy & $30(5)$ & 10 & 20 & $50(37-70)$ & $15.3(3.52)$ & $9(5-15)$ \\
\hline Hernia & $14(2.3)$ & 12 & 2 & $42(29-58)$ & $5.9(2.4)$ & $2(2-5.5)$ \\
\hline Other procedures & 24 & 13 & 8 & $42(33-54)$ & $9.8(4.2)$ & $5(3-11)$ \\
\hline Overall & 605 & 458 & 147 & $37(25-52)$ & $10(0.6)$ & $4(2-11)$ \\
\hline
\end{tabular}

$\mathrm{N}$ : number. M: male. F: female. SEM: standard error of mean. IQR: interquatile range. AAA: abdominal aortic aneurysm. EVAR: endovascular aneurysm repair. IVDU: intravenous drug usage. DUP: duodenal ulcer perforation.

The overall median length of stay of surgical emergency patients was 4 (IQR 2-8) days. This was significantly shorter than the mean length of stay for both elective and emergency cases in all specialties in the UK (7.1 days) as reported by HES (Hospital Episodes Statistics) online in 2003-2004 and reflects the dynamic nature of emergency surgical admissions. [14] Older patients and vascular emergencies (also an older cohort) tended to stay longer possibly due to co-morbidities. $[4,10,15,16]$ The discharge delays were often due lack of provision of social services and rehabilitation after discharge. $[14,16,17]$ Polytrauma patients also tended to stay longer. It is interesting that despite RCTs showing a shortened stay for laparoscopic procedures over open procedures, this is not always borne out in day-to-day clinical practice, for proce- dures such as appendicectomy (median stay of 3 days for laparoscopic versus 2 days for open procedure). [18]

\section{Types of operation}

The emergency operation rate (43.5\%) was much higher compared to around $30.3 \%$ in other series. [9] This could be due to the high number of trauma patients and tertiary referral status or perhaps just a higher threshold for admitting patients, due to availability of investigations in ER. Incision and drainage of abscess (I\&D), the commonest operation was performed in $22.5 \%$ of all operative cases. This again differs from all previous studies in which the commonest emergency procedure was appendicectomy (15\% appendicectomy Dawson study, 11\% in Stower study). $[2-4,10,15]$ However the abscesses stayed for a 


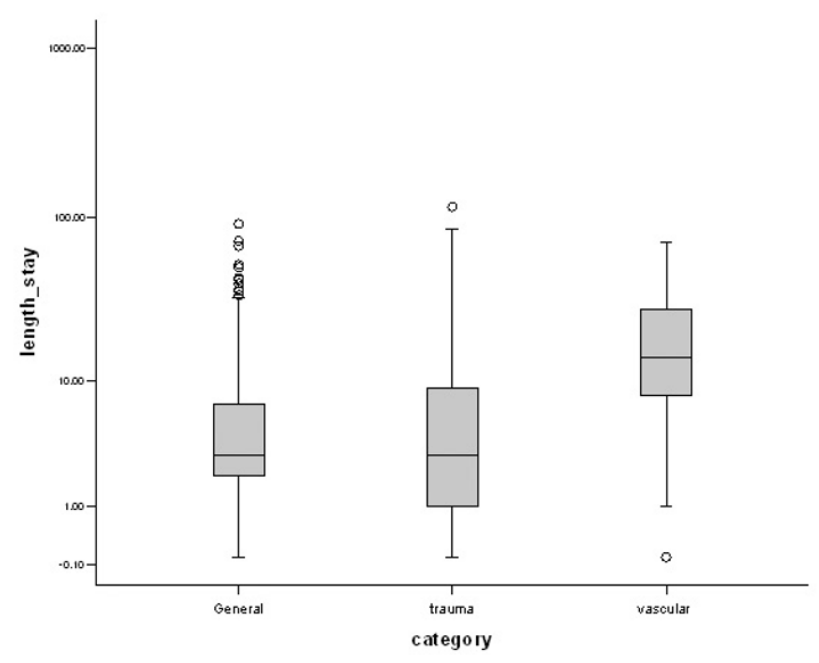

Figure 5

Median length of stay according to specialties. Results are expressed as median \pm Interquartile range. $Y$-axis is log transformed.

median of two days (two overnight stays, the first of them being for waiting for a theatre slot). This may reflect the lower prioritization for emergency theatre space, given other demands in a major trauma center, where only one theatre is fully staffed for emergency general surgical operations. Better theatre and admission planning would be required. A current pilot scheme looks at discharge from A\&E followed by same/next day admission for urgent surgery (such as I\&D) on a planned emergency list. It is inter-

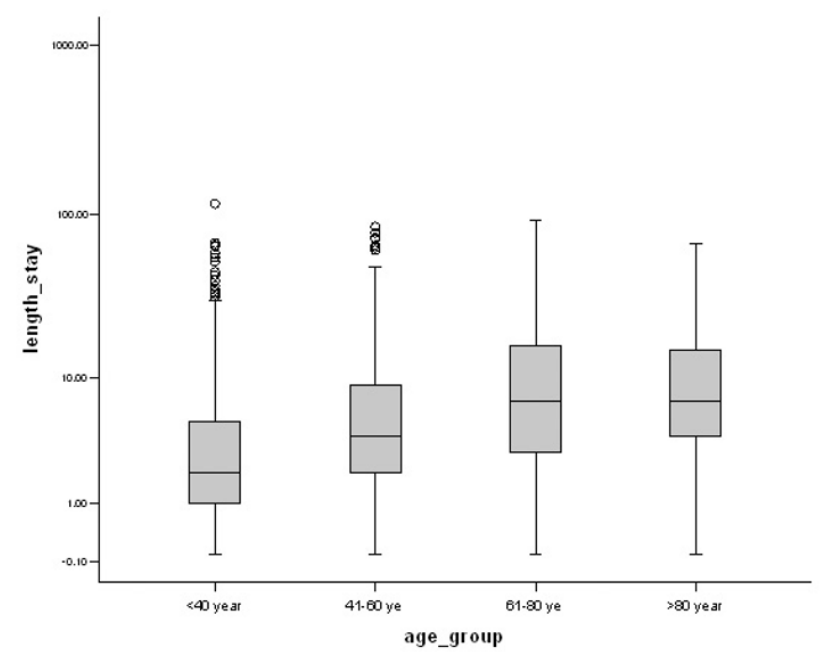

Figure 6

Median length of stay according to age groups. Results are expressed as median \pm Interquartile range. $Y$-axis is log transformed. esting to note that though the admission sex ratio (M:F) was $1.7: 1$, the ratio for operation was $3.1: 1$ (tables 1 and 2 ). This is due to male predominance for trauma patients (requiring a higher rate of operative interventions) and female predominance for non-specific abdominal pain, gall bladder and diverticular disease as well as gynaecological conditions; all of which had lower intervention rate. Thus, only operations such as diagnostic laparoscopies, other laparotomies (often diagnostic and for diverticular disease) and emergency laparoscopic cholecystectomy were more common for women.

\section{Training}

A major trauma centre and tertiary teaching hospital offers an array of training opportunities for the trainee surgeon through exposure to a wide-range of poly-trauma and emergency surgical patients requiring urgent surgical decisions and frequent operative intervention and a rapid turnover. [19] With the introduction of European Working Time Directive (EWTD, an Europe-wide legislation leading to reduction of average working hours from 72 hours to 48 hours) [20] and consequent reduction in the exposure to elective surgery, the findings of this study suggest that trainees gain valuable experience from exposure to a broad spectrum of emergency surgery in a major trauma centre. This fact should be reflected in their training curriculum and log-book. Data such as these should also be considered for workforce planning during reorganisation and rationalisation of health services similar to those planned for London [6]

\section{Authors' contributions}

TAMP collected and analysed data, BP, MW, ATA were instrumental in deciding the type of data to be collected and in formulating the study design and contributed critically at all meetings during the progress of this research, HMK conceived the idea, directed the research, analysed data and wrote the paper. All authors read and approved the final manuscript.

\section{Acknowledgements}

TA Mai-Phan was funded by Vietnam Overseas Scholarship Program (VOSP) of Vietnam's Ministry of Education and Training for his MSc studentship. HM Kocher is funded by the Department of Health (UK) Clinician Scientist Fellowship. The funding bodies for both TAM-P and HMK had no role to play in the data collection, interpretation or analysis of the data, or drafting the manuscript.

\section{References}

I. Capewell S: The continuing rise in emergency admissions. $\mathrm{Bmj}$ 1996, 3 I 2(7037):99|-992.

2. Cobb RA, Baigrie RJ, Reece-Smith H, Faber RG: The workload of a surgical unit in a district general hospital. Ann R Coll Surg Engl 1989, 7 I(5):299-302.

3. Dawson EJ, Paterson-Brown S: Emergency general surgery and the implications for specialisation. Surgeon 2004, 2(3): I65-I 70.

4. Allen-Mersh TG, Earlam RJ: General surgical workload in England and Wales. Br Med J (Clin Res Ed) 1983, 287(6399): I | I5-I I I8. 
5. Tower Hamlets Public Health Report [http://www.publi chealth.thpct.nhs.uk/PublicHealthReport/index.aspx?pid=-2]

6. Darzi A: NHS Next Stage Review Interim Report. [http:// www.ournhs.nhs.uk/fromtypepad/2834II OurNHS v3acc.pdf].

7. Kirk CJ, Earlam RJ, Wilson AW, Watkins ES: Helicopter Emergency Medical Service operating from the Royal London Hospital: the first year. Br J Surg 1993, 80(2):218-221.

8. London Air Ambulance [http://www.hems-london.org.uk]

9. Bain IM, Kirby RM, Cook AL, Oakley PA, Templeton J: Role of the general surgeon in a British trauma centre. Br J Surg 1996, 83(9):|248-|25|.

10. Campbell WB, Lee EJ, Van de Sijpe K, Gooding J, Cooper MJ: A 25year study of emergency surgical admissions. Ann $R$ Coll Surg Engl 2002, 84(4):273-277.

II. Irvin TT: Abdominal pain: a surgical audit of II 90 emergency admissions. Br J Surg 1989, 76(II): I I 2I-II 25.

12. Stower MJ, Hardcastle JD, Bourke JB: Surgical emergencies and manpower. Ann R Coll Surg Engl 1984, 66(2): 1 I7- II9.

13. Dookeran KA, Thompson MM, Lloyd DM, Everson NW: Audit of general practitioner referrals to an acute surgical unit. $\mathrm{BrJ}$ Surg 1992, 79(5):430-431.

14. Hospital Episode Statistic (HES) online [http://www.heson line.nhs.uk/Ease/servlet/ContentServer?sitelD=1937\&catego rylD=537.

15. Campbell WB, Ridler BM, Thompson JF: Providing an acute vascular service: two years experience in a district general hospital. Ann R Coll Surg Engl 1996, 78(4 Suppl): 185-189.

16. Salem $R$, Devitt $P$, Johnson J, Firmin R: Emergency geriatric surgical admissions. $\mathrm{Br}$ Med J 1978, 2(6134):416-417.

17. Houghton A, Bowling A, Jones I, Clarke K: Appropriateness of admission and the last $\mathbf{2 4}$ hours of hospital care in medical wards in an east London teaching group hospital. Int J Qual Health Care 1996, 8(6):543-553.

18. Germanos S, Gourgiotis S, Kocher HM: Clinical update: early surgery for acute cholecystitis. Lancet 2007, 369(9575): I774-I776.

19. Aylwin CJ, Konig TC, Brennan NW, Shirley PJ, Davies G, Walsh MS, Brohi K: Reduction in critical mortality in urban mass casualty incidents: analysis of triage, surge, and resource use after the London bombings on July 7, 2005. Lancet 2006, 368(9554):2219-2225.

20. The Working Time Regulation [http://www.opsi.gov.uk/si/ sil $998 / 19981833 . \mathrm{htm}]$

Publish with Biomed Central and every scientist can read your work free of charge

"BioMed Central will be the most significant development for disseminating the results of biomedical research in our lifetime. "

Sir Paul Nurse, Cancer Research UK

Your research papers will be:

- available free of charge to the entire biomedical community

- peer reviewed and published immediately upon acceptance

- cited in PubMed and archived on PubMed Central

- yours - you keep the copyright
BioMedcentral 